\title{
Reação leucemoide e anemia hemolítica grave causada por Mycoplasma pneumoniae
}

\section{Leukemoid reaction and severe hemolytic anemia due to Mycoplasma pneumoniae}

Kléber G. Luz $^{l}$

Roberto M. Mendonça ${ }^{2}$

Ricardo H. M. Félix ${ }^{2}$

Tásia A. F. Feitosa ${ }^{3}$

Telma C. B Freire
Hemólise massiva é uma manifestação rara da infecção por Mycoplasma pneumoniae. $\dot{E}$ desencadeada por crioaglutininas, anticorpos IgM, que surgem sete a dez dias após a infecção em cerca de 50\% a 75\% dos casos. Hiperleucocitose é também evento incomum e orienta o diagnóstico para etiologia bacteriana ou neoplásica. Relatamos um caso de um homem de 67 anos com pneumonia por Mycoplasma pneumoniae, que apresentou anemia grave e reação leucemoide, diagnosticada por meio do teste de crioaglutininas à beira do leito e dosagem do título de anticorpo antimycoplasma. Após início do tratamento adequado, houve melhora importante da anemia e a leucometria foi reduzida de $56.100 / \mathrm{mm}^{3}$ para valores próximos do normal. Rev. Bras. Hematol. Hemoter.

Palavras-chave: Mycoplasma pneumoniae; anemia hemolitica; leucocitose.

\section{Introdução}

O Mycoplasma pneumoniae ( $M p)$ é um agente infeccioso que causa infecção do trato respiratório. ${ }^{1}$ São os menores organismos com capacidade autorreplicativa, tanto em dimensões celulares quanto de genoma. ${ }^{2}$ Responde por $15 \%$ a $20 \%$ de todos os casos de pneumonia adquirida da comunidade (PAC), sendo o segundo agente causal mais frequente. ${ }^{1}$

Metade dos infectados desenvolve sintomas, a maioria com acometimento do trato respiratório superior, e $25 \%$ desses apresentam manifestações extrapulmonares. ${ }^{3}$ Quadros pneumônicos indicam maior gravidade e são mais frequentes em crianças e idosos. ${ }^{1}$ As queixas geralmente contrastam com a escassez de achados. A patogenicidade do $M p$ engloba tanto a citotoxicidade direta quanto mecanismos imunomediados, como a formação de anticorpos, ativação de complemento e deposição de imunocomplexos. ${ }^{4}$
A anemia hemolítica grave é incomum e desencadeada por reação com crioaglutininas, que surgem de uma a duas semanas após a infecção. Estes anticorpos estão presentes em $50 \%$ dos casos, resultando em hemólise subclínica com discreto aumento da contagem de reticulócitos. ${ }^{3}$ A leucocitose acontece em menos de $30 \%$ dos acometidos e, em geral, é pouco significativa. ${ }^{1}$

Apresentamos um relato de caso de pneumonia por $M p$, que evoluiu com anemia hemolítica grave e reação leucemoide, combinação extremamente rara, tornando o caso um desafio ao diagnóstico.

\section{Relato de Caso}

Um homem de 67 anos, casado, agricultor, foi admitido no HGT - Natal/RN, por rebaixamento do nível de consciência há um dia. Ele era previamente hígido, e familiar relatou que o mesmo, há vinte dias, queixava-se de quadro gripal e evoluiu

\footnotetext{
Médico infectologista. Professor da disciplina de Doenças Infecciosas e Parasitárias, Universidade Federal do Rio Grande do Norte, Natal-RN.

Aluno do curso de Medicina da Universidade Federal do Rio Grande do Norte, Natal-RN.

${ }^{3}$ Médica infectologista. Médica do Hospital Giselda Trigueiro, Natal-RN.

${ }^{4}$ Médica onco-hematologista. Médica do Hospital Giselda Trigueiro, Natal-RN.
}

Hospital Giselda Trigueiro, Natal-RN.

Correspondência: Kléber Giovanni Luz

Rua Desembargador Túlio Bezerra de Melo, 3631, apto 1000

Edificio Alfredo Xavier - Candelária

59064-585 - Natal-RN - Brasil

E-mail:luz@ufrnet.br 
com febre diária, tosse, expectoração amarelada, cefaleia, dor torácica e hiporexia, progredindo no dia da admissão com um episódio de hemoptise e síncope. Na admissão, observou-se significativa palidez cutânea mucosa, desidratação, icterícia, taquipneia, taquicardia, além de estertores finos bibasais na ausculta torácica. A radiografia de tórax revelou infiltrado alveolar multifocal no campo médio e inferior do pulmão direito.

Exames laboratoriais revelaram: $\mathrm{AB}+, \mathrm{Hb}: 4,5 \mathrm{~g} / \mathrm{dl}, \mathrm{Ht}$ : 9\%, leucócitos: $43,5 \times 10^{9} / \mathrm{L}$ (78\% segmentados, $5 \%$ bastões, $15 \%$ linfócitos), plaquetas: $437 \times 10^{9} / \mathrm{L}$; ureia: $77 \mathrm{mg} / \mathrm{dl}$ (0-45 mg/dl) ; creatinina: $0,54 \mathrm{mg} / \mathrm{dl}(0,2-1,4 \mathrm{mg} / \mathrm{dl})$; AST: 67 U/l (0-45 U/1);ALT: 37 U/1 (0-40 U/1); INR 1; LDH: 1.016 U/1 (200-400 U/l); bilirrubinas totais: $2,45 \mathrm{mg} / \mathrm{dl}(0-1,2 \mathrm{mg} / \mathrm{dl})$; bilirrubina indireta: $1,84 \mathrm{mg} / \mathrm{dl}(0-0,8 \mathrm{mg} / \mathrm{dl})$; coombs direto positivo $4+$. Diante do quadro de pneumonia e anemia hemolítica autoimune foram feitas as hipóteses de infecção pelo $\mathrm{Mp}$ e em neoplasias linfo-hematopoéticas, devido à excessiva leucocitose.

Foi iniciado levofloxacina $500 \mathrm{mg} /$ dia com evidente melhora clínica, entretanto os dados hematimétricos não melhoravam, com a leucometria atingindo cifras de $56,1 \times 10^{9} / \mathrm{L}$ com $83 \%$ de segmentados e LDH: 1.055 U/1. Diante da possibilidade de infecção por $M p$ foi realizada a pesquisa de crioaglutininas à beira do leito, sendo esta positiva; sumário de urina revelou urobilinogênio 2+; esfregaço de sangue periférico revelou granulócitos maduros com granulações tóxicas, corpos de Dohle e vacuolização citoplasmática, não evidenciando células jovens nem restos nucleares, policromatofilia ++ , microesferócitos + e $44 \%$ de eritroblastos. Prednisona foi iniciada na dose de $120 \mathrm{mg} /$ dia.

No $12^{\circ}$ dia apresentava Ht: 17,3\%, leucócitos 16,6 x $10^{9} / \mathrm{L}$; reticulócitos: $21,3 \%$, índice de produção reticulocitária: 4,61. Pesquisa quantitativa de crioaglutininas foi reativa até 1:256 e sorologia (imunoensaio enzimático) reagente para anticorpos IgM antimycoplasma, $4.467 \mathrm{U} / \mathrm{ml}$ ( $0-770$ correspondendo a negatividade), confirmando a infecção por mycoplasma.

O paciente foi de alta hospitalar em 15 dias de internação com Hb: 9,4 g/dl, Ht: 28\%, leucócitos: 11,9 x 10\%/L (55\% segmentados, $1 \%$ bastões, $40 \%$ linfócitos), plaquetas: $135 \mathrm{x}$ 10 $/ \mathrm{L}$, ureia: $44 \mathrm{mg} / \mathrm{dl}$, creatinina: 0,8 mg/dl, LDH: $437 \mathrm{U} / 1$; em desmame do corticoide, bom estado geral e assintomático.

\section{Discussão}

A primeira publicação referente ao mycoplasma ocorreu em 1898 durante investigação do agente causador da pleuropneumonia bovina, por Nocard e Roux. ${ }^{5}$ Já o $M p$ foi, pela primeira vez, isolado do escarro de um indivíduo com pneumonia atípica, por Eaton, em $1944 .{ }^{6}$

Além das manifestações respiratórias, presentes em metade dos infectados, o que torna o caso peculiar é a hemólise maciça associada a reação leucemoide, pouco descrita na literatura. ${ }^{4,-11}$ A contagem de leucócitos é normal em $75 \%$ a $90 \%$ dos casos ${ }^{12}$ e leucocitose importante deve levantar a suspeita de infecção bacteriana de outra causa ou natureza neoplásica. No relato, a máxima leucometria foi de $56,1 \times 10^{9} / \mathrm{L}$, entretanto, o número excessivo de eritroblastos no sangue periférico, ocasionado pela crise hemolítica, pode ter superestimado a contagem granulocítica.

A hemólise geralmente não é muito importante e ocorre quando há títulos de crioaglutininas muito elevados. Há relato de queda na concentração de hemoglobina superior a $2 \mathrm{~g} / \mathrm{dl}$ em $12,8 \%$ dos casos, ${ }^{13}$ podendo estar presente elevação da contagem de reticulócitos em $64 \%$ das infecções. ${ }^{14}$ No caso, observou-se hemólise acentuada, sugerida pela elevação da bilirrubina indireta, LDH e coombs fortemente reativo, desencadeando anemia grave (Ht: 9\%), o que contribuiu ainda mais para o agravamento do quadro.

Crioaglutininas são anticorpos IgM produzidos sete a dez dias após a infecção em cerca de $50 \%$ a $75 \%$ dos casos e podem persistir por dois a três meses. Essas imunoglobulinas oligoclonais são dirigidas contra o antígeno I, na superfície das hemácias, ligando-se a uma temperatura de $4^{\circ} \mathrm{C} .{ }^{3}$ Uma teoria refere que a bactéria altera a estrutura deste polissacarídeo tornando-o antigênico, possivelmente por meio do peróxido de hidrogênio; outra afirma que o antígeno no estado de sialonato pode servir como receptor para o mycoplasma e os anticorpos se orientariam contra esse receptor modificado. Estudos indicam que as crioaglutininas são dirigidas contra estruturas bacterianas e podem ter reação cruzada com o antígeno. ${ }^{15}$ Por meio da ativação do complemento, as hemácias ligadas aos anticorpos são destruídas, ${ }^{16}$ sendo a hemólise maciça, como visto neste caso, um evento raro. ${ }^{3}$ Coombs direto é positivo em muitos indivíduos. ${ }^{15}$

Infecção por $M p$ não pode ser diagnosticada apenas por achados clínicos, especialmente quando há manifestações extrapulmonares. ${ }^{17}$ Além disso, achados laboratoriais são pouco sugestivos. Dessa forma, a pesquisa de crioaglutininas deve ser realizada diante da suspeita clínica. Uma forma simples de detecção foi realizada à beira do leito, utilizando-se do teste de aglutinação-dissociação. Griffin ${ }^{18}$ foi o pioneiro na técnica, a qual pode ser repetida várias vezes seguidas, apresentando o mesmo resultado, e sugere um título laboratorial de crioaglutininas superior a 1:64, ${ }^{19}$ lembrando que um quadro clínico sugestivo associado a uma titulação superior a 1:32 é altamente indicativo de infecção por Mycoplasma. ${ }^{15}$

Métodos sorológicos são os mais utilizados para o diagnóstico e incluem ELISA, fixação por complemento ou aglutinação passiva. Dentre esses, o primeiro é uma boa opção, pois é tão sensível quanto Reação em Cadeia da Polimerase (PCR) e mais sensível que cultura para infecções agudas. PCR pode ser utilizado devido a sua alta sensibilidade, mas é incapaz de distinguir infecção de colonização. A cultura é o método padrão-ouro, mas, além de dispendiosa, requer muito tempo e é pouco disponível. ${ }^{3,17} \mathrm{~A}$ acurácia dos testes sorológicos é otimizada quando a soroconversão é verificada, sendo necessário quantificar anticorpos na fase aguda e de conva- 
lescência da doença. A soroconversão é definida quando há quadruplicação dos títulos entre esses dois períodos ou um único título de fixação por complemento superior a 1:128. ${ }^{17}$

Para o caso analisado, a pesquisa de crioaglutininas à beira do leito foi reativa, a pesquisa quantitativa de crioaglutininas positiva 1:256 e ELISA reativo para $\operatorname{IgM} 4.467 \mathrm{U} / \mathrm{ml}$ confirmando a infecção. Em locais de poucos recursos, o teste à beira do leito é uma opção na suspeita de infecção por $M p$, pois é de fácil realização, baixo custo, direcionando o diagnóstico e terapêutica.

Formação de crioaglutininas também ocorre em outros contextos clínicos, que devem ser investigados no diagnóstico diferencial, incluindo afecções inflamatórias e hematológicas como LES, mieloma múltiplo, linfomas, LLC e infecções como EBV, CMV, HCV. ${ }^{3,7,15,17}$

As manifestações extrapulmonares acometem $25 \%$ dos pacientes e $25 \%$ apresentam alterações cutâneas, seguido do acometimento músculo-esquelético (14\%), cardíaco $(8,5 \%)$, SNC $(0,4 \%)$ e sanguíneo. ${ }^{4}$ Neste grupo já foram descritos CIVD, tromboembolismo, PTT e síndrome histiocítica hemofagocítica. ${ }^{3,4,15,17}$ Trombocitose pode ocorrer e está relacionada a resposta de fase aguda, sendo trombocitopenia incomum. ${ }^{12}$

A radiografia de tórax é variável e se manifesta principalmente como opacidades reticulares difusas de broncopneumonia em regiões peri-hilar ou em lobos inferiores, usualmente com distribuição unilateral e adenopatia hilar., ${ }^{3,15}$ Uma característica marcante desta infecção é a dissociação clínico-radiológica, pois, como no caso, pobreza de achados radiológicos podem ter repercussões clínicas importantes.

Apesar da anemia grave, não foi indicada terapia transfusional devido ao risco de hemólise. O uso de esteroides não é geralmente indicado no tratamento da anemia hemolítica, apesar de ter mostrado benefício em alguns trabalhos. ${ }^{10,20}$ Antibioticoterapia é necessária e envolve agentes que atuam na síntese proteica, sendo os macrolídeos a primeira escolha. ${ }^{3,15,17}$

\footnotetext{
Abstract

Massive hemolysis, a rare manifestation of Mycoplasma pneumoniae infection, is due to cold agglutinins (IgM antibodies) that appear seven to ten days after the infection in around $50 \%$ to $70 \%$ of cases. Hyperleukocytosis, suggestive of bacterial or neoplastic etiologies, is also an uncommon event. We report here on the case of a 67-year-old man with Mycoplasma pneumoniae pneumonia who presented with severe anemia and leukemoid reaction as diagnosed by the bedside cold agglutinin test and measurement of anti-mycoplasma antibodies. After beginning appropriate treatment, the anemia improved significantly and the leukocyte count reduced from $56100 \mathrm{~mm}^{3}$ to close to normal level. Rev. Bras. Hematol. Hemoter.
}

Key words: Mycoplasma pneumoniae; hemolytic anemia; leukocytosis.

\section{Referências Bibliográficas}

1. Costa MJM. Infecção por Mycoplasma e Clamydia. In: Lopes, A.C. eds. Tratado de Clínica Médica, São Paulo: Roca, 2006.

2. Wilson MH, Collier AM. Ultrastructural study of Mycoplasma pneumoniae in organ culture. J Bacteriol. 1976;125(1):332-9.

3. Waites KB, Talkington DF. Mycoplasma pneumoniae and its role as a human pathogen. Clin Microbiol Rev. 2004;17(4):697-728.

4. Wilson ML, Menjivar E, Kalapatapu V, Hand AP, Garber J, Ruiz MA. Mycoplasma pneumoniae associated with hemolytic anemia, cold agglutinins, and recurrent arterial thrombosis. South Med J. 2007;100(2):215-8

5. Nocard E, Roux ER. Le microbe de la peripneumonie. Ann Inst Pasteur. 1898;12:240-262.

6. Eaton MD, Meikejohn G, van Herick W. Studies on the etiology of primary atypical pneumonia: a filterable agent transmissible to cotton rats, hamsters, and chick embryos. J Exp Med. 1944;79(6):649-67.

7. Daxböck F, Zedtwitz-Liebenstein K, Burgmann H, Graninger W. Severe hemolytic anemia and excessive leukocytosis masking mycoplasma pneumonia. Ann Hematol. 2001;80(3):180-2.

8. Shulman ST, Bartlett J, Clyde WA, Ayoub EM. The unusual severity of mycoplasmal pneumonia in children with sickle-cell disease. N Engl J Med. 1972;287(4):164-7.

9. Husain MH, Abdulrahman HI, Abdulqader B. Mycoplasma pneumonia associated with severe autoimmune hemolytic anemia. Kuw Med J. 2004;36 (2):131-3.

10. Chu CS, Braun SR, Yarbro JW, Hayden MR. Corticosteroid treatment of hemolytic anemia associated with Mycoplasma pneumoniae pneumonia. South Med J. 1990;83(9):1106-8.

11. Kottayam R, Rozenberg G, Cohn RJ. Unusual haematologic manifestations of Mycoplasma pneumoniae infection. J Paediatr Child Health. 2007;43(1-2):80-2.

12. Marrie TJ. Mycoplasma pneumoniae pneumonia requiring hospitalization, with emphasis on infection in the elderly. Arch Intern Med. 1993;153(4):488-94.

13. Ali NJ, Sillis M, Andrews BE, Jenkins PE, Harrison BD. The clinical spectrum and diagnosis of Mycoplasma pneumoniae infection. Q J Med. 1986;58(227):241-51.

14. Feizi T. Cold agglutinins, the direct coombs' test and serum immunglobulins in Mycoplasma pneumoniae infection. Ann N Y Acad Sci. 1967;143(1):801-12

15. Baum SG. Mycoplasma pneumoniae and atypical pneumonia. In: Mandell, Douglas and Bennetts. Principles and Practice of Infectious Diseases, $6^{\text {th }}$ Ed, Vol 2, Philadelphia, Pa: Elsevier Churchill Livingstone, 2005:2271-80.

16. Kirschfink, M, Knoblauch, K, Roelcke, D. Activation of complement by cold agglutinins. Infusionsther Transfusionsmed 1994;21(6):405.

17. Sánchez-Vargas FM, Gómez-Duarte OG. Mycoplasma pneumoniaean emerging extra-pulmonary pathogen. Clin Microbiol Infect. 2008;14(20):105-15.

18. Griffin JP. Rapid screening for cold agglutinins in pneumonia. Ann Intern Med. 1969;70(4):701.

19. Cunha BA. The clinical diagnosis of Mycoplasma pneumoniae: the diagnostic importance of highly elevated serum cold agglutinins. Eur J Clin Microbiol Infect Dis. 2008;27(10):1017-19.

20. Tsuruta R, Kawamura Y, Inoue T, et al. Corticosteroid therapy for hemolytic anemia and respiratory failure due to Mycoplasma pneumoniae pneumonia. Intern Med. 2002;41(3):229-32.

Avaliação: Editor e dois revisores externos

Conflito de interesse: sem conflito de interesse

Recebido: 24/03/2009

Aceito após modificações: 04/06/2009 